CLINICAL STUDY

\title{
Testicular size development and reproductive hormones in boys and adult males with Noonan syndrome: a longitudinal study
}

\author{
Carina Ankarberg-Lindgren, Otto Westphal and Jovanna Dahlgren \\ Department of Pediatrics, Institute of Clinical Sciences, Göteborg Pediatric Growth Research Center, The Queen Silvia Children's Hospital, The Sahlgrenska \\ Academy at University of Gothenborg, S-416 85 Göteborg, Sweden
}

(Correspondence should be addressed to J Dahlgren; Email: jovanna.dahlgren@vgregion.se)

\begin{abstract}
Objective: To characterise changes in testicular size and reproductive hormones and to investigate the aetiology of delayed puberty and impaired fertility in males with Noonan syndrome (NS).

Design: In this study, 12 males with NS were longitudinally followed from pre/early puberty until adulthood. Of the 12 males, ten had no medical history other than NS and were divided into two groups, undescended testes (UT), and descended testes (DT) and compared with a reference population. Methods: Hormone concentrations in serum were determined by immunoassays and testicular volume was measured using an orchidometer.

Results: Before puberty, reproductive hormone levels were within the expected range in almost all cases. In some cases, LH, FSH and testosterone and oestradiol $\left(\mathrm{E}_{2}\right)$ concentrations started to increase during puberty and inhibin B and anti-Müllerian hormone (AMH) declined to subnormal levels. Most of the boys studied had small testes that, in the majority of cases, progressed to normal size in adulthood. No difference in reproductive hormones was observed between the UT and DT groups either during puberty or at adulthood. However, as adults, males with NS had higher LH (5.7 vs 4.0 U/1, $P<0.01)$, FSH (7.1 vs $2.5 \mathrm{U} / \mathrm{l}, P<0.001)$, testosterone (18.7 vs $15.6 \mathrm{nmol} / \mathrm{l}, P<0.01)$ and $\mathrm{E}_{2}(66 \mathrm{vs}$ $46 \mathrm{pmol} / \mathrm{l}, P<0.001$ ) levels and lower AMH (33 vs $65 \mathrm{pmol} / \mathrm{l}, P<0.01$ ) and inhibin B (median $108 \mathrm{vs}$ $187 \mathrm{pg} / \mathrm{ml}, P<0.01)$ levels than the reference population.

Conclusions: In NS males, both Sertoli and Leydig cell dysfunction is common with reproductive hormone levels deteriorating progressively to adulthood.
\end{abstract}

European Journal of Endocrinology 165 137-144

\section{Introduction}

Noonan syndrome (NS) is an autosomal dominant disorder characterised by a phenotype including short stature, facial dysmorphology and congenital heart defects. In $\sim 50 \%$ of cases, NS is caused by mutations in the PTPN11 gene (1). In both sexes, there is a delay in pubertal development $(2,3)$. Fertility appears to be normal in females but has been reported to be decreased in males (4), although male transmission of the disorder to the next generation is not uncommon. A possible cause of impaired male fertility is undescended testes (UT), reported in $60-77 \%$ of boys with NS $(3,5)$. UT are associated with impaired fertility $(6,7)$. A small number of males with NS have had assessment of gonadal function in prepubertal period (2) as well as adulthood (8-10).

Theintz \& Savage (2) reported an elevated LH response in five prepubertal boys with NS who were surgically treated for maldescended testes. Sinisi et al. (8) and Elsawi et al. (9) studied four and 11 males with NS respectively. Half of the males in these studies had been surgically treated for bilateral UT during childhood. As adults, those with a history of bilateral UT had azoospermia, elevated FSH levels and normal or elevated LH levels, whereas all of the men with descended testes (DT) had normal hormone levels. Unexpectedly, Marcus et al. (10) studied nine males and observed raised FSH and subnormal inhibin B concentrations in all three men with DT, indicating a primary gonadal dysfunction in males with NS.

The male hypothalamo-pituitary-gonadal axis is active from fetal life and regulates both the onset of puberty and spermatogenesis. The testosterone loop is also established in fetal life, and there is an important rise in gonadotropins and testosterone during early infancy. FSH is necessary for the initial establishment of mature germinal epithelium and also the initiation of spermatogenesis early in puberty through Sertoli cell proliferation. Sertoli cell maturation is accompanied by increasing inhibin $\mathrm{B}$ and testosterone levels, but declining anti-Müllerian hormone (AMH) levels (11, 12). From fetal life until puberty, testes produce high levels of AMH and secretion is induced by FSH but inhibited by testosterone. Testosterone also stimulates the early FSH-independent increase in inhibin B that 
precedes puberty. Moreover, inhibin B is germ cell independent before puberty and germ cell dependent after puberty. Therefore, inhibin B is commonly seen as a sensitive marker of germ cell damage in adults (13), whereas AMH reflects Sertoli cell function and testicular androgen action (reviewed in (14)). In addition, AMH and inhibin B are clinically used to assess the presence and function of Sertoli cells during childhood.

The association between indices of fertility and concentrations of gonadotropins, inhibin $\mathrm{B}$ and sex steroids is well described in healthy men $(13,15)$ and in men with bilateral UT $(7,16)$. Together, these studies and the studies in males with NS, suggest that UT could be the principal but not the sole cause of impaired fertility. The question is to what extent abnormal gonadal function in males with NS is simply a consequence of UT or if it reflects a more fundamental hormonal dysfunction or testes dysgenesis. To investigate this study, testicular volume and hormonal status were monitored longitudinally from the beginning of puberty to adulthood.

\section{Study subjects and methods}

\section{Males with NS}

The study group comprised of 12 males diagnosed with NS. All were investigated at the Queen Silvia Children's Hospital in Göteborg, Sweden. Diagnoses were made by a single clinician (OW) based on the following major criteria: short stature, hypertelorism, low set ears and low set hairline, and at least one minor criterion: malformation of the thorax, ptosis, cubitus valgus, webbed neck, pulmonary stenosis and cryptorchidism. Subjects had normal thyroid function, normal karyotype, no major heart disease and were well nourished. Kidney and liver functions were normal. All subjects were treated with GH due to short stature (growth data previously reported) (17). None of the subjects were $\mathrm{GH}$ deficient.

The study was approved by the Ethics Committee of the Faculty of Medicine at the Sahlgrenska Academy, University of Gothenburg, and carried out in accordance with the Declaration of Helsinki. Written informed consent was obtained from the subjects and their parents.

\section{Pubertal classification}

Stage of puberty was evaluated every 6-12 months until adulthood. During each assessment, testicular volumes were determined using an orchidometer (18). Pubertal stage was classified according to the largest of the testes or testis in situ using the following stages: pre (testis 1-2 ml), early (testis 3-6 ml), mid (testis $8-12 \mathrm{ml})$ and late $(15-25 \mathrm{ml})$ puberty as defined previously (19). According to this classification, ten boys were prepubertal and two (subjects 1 and 7 ) were

Table 1 Clinical, genital and gene data in 12 males with Noonan syndrome.

\begin{tabular}{|c|c|c|c|c|c|c|c|}
\hline \multirow{2}{*}{$\begin{array}{l}\text { Subject } \\
\text { no. }\end{array}$} & \multicolumn{2}{|c|}{ Age at sampling (years) } & \multicolumn{2}{|c|}{ Testis size at adult age (ml) } & \multirow[b]{2}{*}{ Medical history } & \multirow{2}{*}{$\begin{array}{l}\text { Age at } \\
\text { surgery for } \\
\text { UT (years) }\end{array}$} & \multirow{2}{*}{$\begin{array}{l}\text { Mutated } \\
\text { PTPN11 } \\
\text { gene }\end{array}$} \\
\hline & First & Last & Largest & Smallest & & & \\
\hline 2 & 9.6 & 21.6 & 20 & Missing & $\begin{array}{l}\text { Surgically treated for } \\
\text { bilateral UT }\end{array}$ & 12.0 & + \\
\hline 3 & 10.9 & 25.7 & 8 & $\begin{array}{l}\text { Not measurable } \\
\text { due to hydrocele }\end{array}$ & $\begin{array}{l}\text { Surgically treated for } \\
\text { bilateral UT. Testis } \\
\text { volume } 20 \mathrm{ml} \text { at } 17.0 \\
\text { years }\end{array}$ & 0.2 & - \\
\hline 4 & 12.1 & 21.4 & 20 & 20 & $\begin{array}{l}\text { Initially, testes seemed } \\
\text { normal. Surgically, trea- } \\
\text { ted for bilateral UT }\end{array}$ & 14.5 & + \\
\hline 5 & 13.6 & 24.5 & 1 & 1 & $\begin{array}{l}\text { Central hypogonadism, } \\
\text { started with HRT at } 16.6 \\
\text { years. Surgically treated } \\
\text { for bilateral UT }\end{array}$ & 5.2 & - \\
\hline 6 & 13.0 & 23.6 & 15 & 12 & $\begin{array}{l}\text { Juvenile arthritis, treated } \\
\text { with methotrexate }\end{array}$ & - & - \\
\hline 7 & 14.2 & 28.9 & 20 & 15 & $\begin{array}{l}\text { Surgically treated for uni- } \\
\text { lateral UT, soft testes }\end{array}$ & 12.3 & + \\
\hline 8 & 13.8 & 20.6 & 20 & 20 & & - & + \\
\hline 9 & 10.7 & 20.1 & 20 & 20 & & - & - \\
\hline 10 & 10.9 & 19.4 & 15 & 15 & $\begin{array}{l}\text { Testes volume } 20 \mathrm{ml} \text { at } \\
18.2 \text { years }\end{array}$ & - & - \\
\hline 11 & 10.1 & 17.0 & 12 & 8 & $\begin{array}{c}\text { Testes volume } 15 \mathrm{ml} \text { at } \\
13.1-14.3 \text { years }\end{array}$ & - & - \\
\hline 12 & 10.1 & 18.2 & 20 & 20 & & - & + \\
\hline
\end{tabular}

UT, undescended testes. 
in early puberty at the beginning of the investigation. Puberty was defined as delayed if a testicular volume of $>3 \mathrm{ml}$ was not reached by the age of 14 years (20). Normal adult testicular volume was defined as $\geq 15 \mathrm{ml}$.

\section{Medical history}

Of the 12 boys with NS, four were surgically treated for bilateral UT and one for unilateral UT (age range 0.2-12.3 years; for individual ages, see Table 1). Another boy was initially found to have DT and was only later diagnosed with bilateral UT and therefore surgery was performed at the age of 14.5 years. One boy was found to have central hypogonadism (not common in subjects with NS) and he was the only subject who received hormone replacement therapy to induce puberty and another male had juvenile arthritis and was treated during puberty with methotrexate, which has a toxic effect on the gonads (subject 6). Both are included in Table 1 but not in further analyses. No other subject had an unusual medical history. Data on individual ages at the first and the last visit, testicular volumes and surgery are presented in Table 1 . The males were divided into two groups: UT and DT.

\section{Methods}

Blood samples were drawn between 0800 and $1400 \mathrm{~h}$. After separation, sera were stored at $-70{ }^{\circ} \mathrm{C}$ until assayed. All samples for hormone determination were assessed in duplicate at GP-GRC accredited laboratory (SS-EN ISO 15189).
Serum oestradiol $\left(\mathrm{E}_{2}\right)$ concentrations were determined using an assay that involves a diethyl ether extraction step prior to quantification by a modified RIA (Spectria Estradiol RIA, Orion Diagnostica; Espoo, Finland) as described previously (21). The lower limit of detection for the extraction RIA was $4 \mathrm{pmol} / \mathrm{l}$. The intra-assay coefficient of variation $(\mathrm{CV})$ was $10-17 \%$, whereas the interassay $C V$ was $19 \%$ for $6 \mathrm{pmol} / \mathrm{l}$ and $8 \%$ for $70 \mathrm{pmol} / \mathrm{l}$.

Serum testosterone concentrations were determined using a modified RIA (Spectria Testosterone RIA; Orion Diagnostica) as described previously (22). The lower limit of detection was $0.03 \mathrm{nmol} / \mathrm{l}$. The intra-assay and interassay $\mathrm{CV}$ were 11 and $15 \%$, respectively, for concentrations of $0.2 \mathrm{nmol} / \mathrm{l}$ and below and $7 \%$ for concentrations above $0.9 \mathrm{nmol} / \mathrm{l}$.

Serum AMH concentrations were determined by AMH Gen II ELISA (Beckman coulter, Inc., Marseille, France). The lower limit of detection was $0.6 \mathrm{pmol} / \mathrm{l}$. The intra-assay $\mathrm{CV}$ was $<7 \%$ and the interassay $\mathrm{CV}$ was $<10 \%$ within the range $25-550 \mathrm{pmol} / \mathrm{l}$.

Serum inhibin B concentrations were determined by Inhibin B Gen II ELISA (Beckman coulter, Inc.). The lower limit of detection was $2.6 \mathrm{pg} / \mathrm{ml}$. The intraassay $\mathrm{CV}$ was $<6 \%$ within the range $70-430 \mathrm{pg} / \mathrm{ml}$. The interassay CV was $8 \%$ for $80 \mathrm{pg} / \mathrm{ml}$ and $<6 \%$ for concentrations above $100 \mathrm{pg} / \mathrm{ml}$.

Serum LH and FSH concentrations were determined using a time-resolved fluoroimmunoassay (AutoDELFIA; Wallac, Turku, Finland). The detection limits were $0.05 \mathrm{U} / \mathrm{l}$ for both. The intra-assay $\mathrm{CV}$ was $<3 \%$. The interassay $\mathrm{CV}$ was $<7 \%$.

Table 2 Ages and reproductive hormone concentrations during pubertal development expressed as medians (ranges) in males with Noonan syndrome (five with UT and five with DT). Puberty was classified according to the largest of the testes or testis in situ.

\begin{tabular}{lcccc}
\hline & \multicolumn{4}{c}{ Pubertal stages } \\
\cline { 2 - 4 } Variables & Pre puberty & Early puberty & Mid puberty & Late puberty \\
\hline Age (years) & & & & \\
UT & $10.9(9.6-12.1)$ & $13.9(11.6-14.2)$ & $14.9(13.6-16.2)$ & $18.1(16.6-19.2)$ \\
DT & $10.7(10.1-13.8)$ & $12.8(11.1-14.8)$ & $14.8(12.1-16.8)$ & $17.0(14.3-17.9)$ \\
LH (U/l) & & & \\
UT & $0.16(0.10-0.3)$ & $0.40(<0.05-3.7)$ & $3.1(0.93-5.0)$ & $3.5(2.3-8.8)$ \\
DT & $0.10(0.07-0.8)$ & $1.2(0.08-1.8)$ & $1.7(1.6-2.8)$ & $4.1(2.1-4.7)$ \\
FSH (U/l) & $1.9(1.2-2.1)$ & $2.2(1.3-12.2)$ & $5.6(2.1-16.0)$ & $13.9(5.7-31.6)$ \\
UT & $1.5(0.8-1.8)$ & $2.2(1.2-4.7)$ & $3.3(1.9-9.0)$ & $4.9(3.9-12.7)$ \\
DT & $0.2(0.2-0.3)$ & $0.5(0.2-12.4)$ & $11.4(4.3-17.2)$ & $19.0(6.6-21.1)$ \\
Testosterone (nmol/l) & $1.4(0.3-4.6)$ & $7.1(3.5-9.7)$ & $14.4(12.2-18.5)$ \\
UT & $0.3(0.1-0.8)$ & & & \\
DT & $6(6-21)$ & $9(6-21)$ & $21(14-40)$ & $70(33-83)$ \\
Oestradiol (pmol/l) & $7(6-12)$ & $13(6-16)$ & $20(13-33)$ & $46(33-53)$ \\
UT & & & & \\
DT & $364(161-793)$ & $344(33-864)$ & $41(26-118)$ & $24(16-33)$ \\
AMH (pmol/l) & $548(428-1035)$ & $139(90-940)$ & $42(20-74)$ & $33(20-79)$ \\
UT & $54(30-78)$ & $116(53-134)$ & $93(41-198)$ & $75(25-213)$ \\
DT & $83(49-164)$ & $174(33-186)$ & $163(54-188)$ & $177(78-194)$ \\
Inhibin B (pg/ml) &
\end{tabular}


Table 3 Serum hormone concentrations subdivided by groups in 44 healthy controls and ten adult males with Noonan syndrome. Data are shown as median (range).

\begin{tabular}{lcccc}
\hline & Controls & Noonan males & $\begin{array}{c}\text { Noonan undescended } \\
\text { testes group }\end{array}$ & $\begin{array}{c}\text { Noonan descended } \\
\text { testes group }\end{array}$ \\
\hline $\boldsymbol{n}$ & 44 & 10 & 5 & 5 \\
$\mathrm{LH}(\mathrm{U} / \mathrm{l})$ & $4.0(1.5-6.9)$ & $5.7(3.5-11.8)^{\star \star}$ & $10.2(4.0-11.8)^{\star \star}$ & $5.2(3.5-6.7)$ \\
$\mathrm{FSH}(\mathrm{U} / \mathrm{l})$ & $2.5(0.7-7.2)$ & $7.1(3.0-32.2)^{\star \star \star}$ & $19.7(3.0-32.2)^{\star \star \star}$ & $5.9(3.8-15.2)^{\star \star}$ \\
Testosterone $(\mathrm{nmol} / \mathrm{l})$ & $15.6(6.5-27.3)$ & $18.7(13.2-25.3)^{\star \star}$ & $18.7(14.7-22.6)^{\star}$ & $18.4(13.2-25.3)$ \\
$\mathrm{E}_{2}(\mathrm{pmol} / \mathrm{l})$ & $46(22-106)$ & $66(52-115)^{\star \star}$ & $63(52-115)^{\star *}$ & $69(54-95)^{\star}$ \\
$\mathrm{AMH}(\mathrm{pmol} / \mathrm{l})$ & $65(26-206)$ & $33(15-63)^{\star \star}$ & $37(15-44)^{\star \star}$ & $29(25-63)^{\star}$ \\
Inhibin B $(\mathrm{pg} / \mathrm{ml})$ & $187(67-295)$ & $108(28-251)^{\star \star}$ & $68(28-251)^{\star}$ & $130(101-203)^{\star}$ \\
\hline
\end{tabular}

${ }^{\star} P<0.05,{ }^{* *} P<0.01$ and ${ }^{* \star} P<0.001$ compared with the control group.

Genetic screening of PTPN11 exons 2-4, 7-8 and 12-13 was performed in all subjects, as described by Tartaglia et al. (1). PCR fragments were either sequenced directly or screened for heterozygous positions using denaturing HPLC followed by sequencing of all fragments.

\section{Normal reference values}

Testicular size during puberty was compared to reference values according to Zachmann et al. (23). Gonadotropin and sex steroid levels in males with NS prior to and during pubertal development were compared with previously published data on hormone levels in healthy subjects (age range 5.0-18.6 years) $(19,24,25)$. The adult control group consisted of 44 healthy males (age range 20.1-24.8 years) and has previously been described (26). Hormonal values of all controls were determined by the same assays at GP-GRC laboratory as the NS group. Normal values for AMH and inhibin $\mathrm{B}$ levels during puberty were not available at the GP-GRC laboratory.

\section{Statistical analysis}

Individual data are presented in the figures, allowing the reader to track every individual subject. Tables 2 and 3 present median values and range for each group and pubertal stage. Mixed between-within ANOVA (SPSS statistics version 17.0, IBM Corp., NY 10589, USA) was used for comparison of hormone concentrations between groups during pubertal development (repeated measures). Owing to two missing values, prepubertal levels were excluded in that analysis. The Mann-Whitney $U$ test was used for comparison of hormone concentrations between groups at adulthood. A $P$ value $<0.05$ was considered significant.

\section{Results}

\section{Start of puberty and testicular size in NS}

Progression of testicular size is presented in Fig. 1. According to the classical classification by Marshall \&
Tanner (20), puberty was delayed in four of the ten males with NS (subjects 3, 4, 7 and 8). All except two of the males with NS had testicular volumes below the median value for controls of the same age during pubertal development. Interestingly, testicular size had diminished after full pubertal maturation in three males (subjects 3,10 and 11). Nevertheless, only two males with NS had subnormal testicular volumes as adults (Fig. 1 and Table 1).

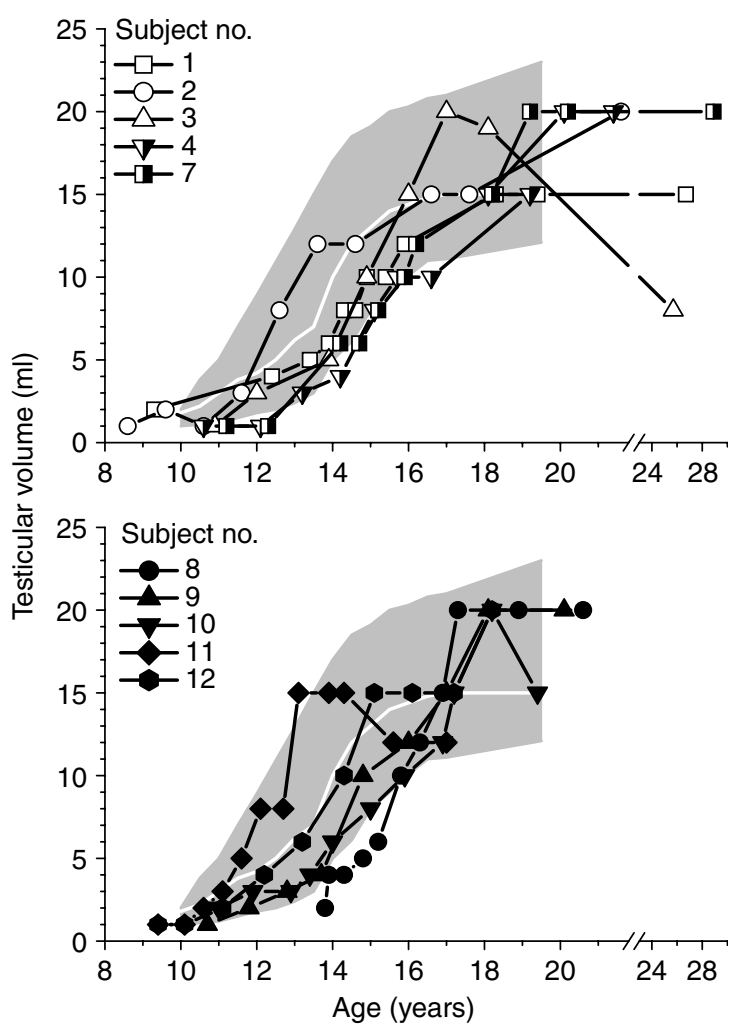

Figure 1 Progression of testicular size in males with NS. Upper panel: Males with undescended testes (UT). Open symbols represent males with bilateral UT, the half-filled triangle represents the male who developed bilateral UT at a late age and the half-filled square represents the patient with unilateral UT. Lower panel: Filled symbols represent males with descended testes. The shaded area indicates the 10th-90th percentiles of the normal testicular growth chart according to Zachmann et al. (23). The white line represents the 50th percentile. 


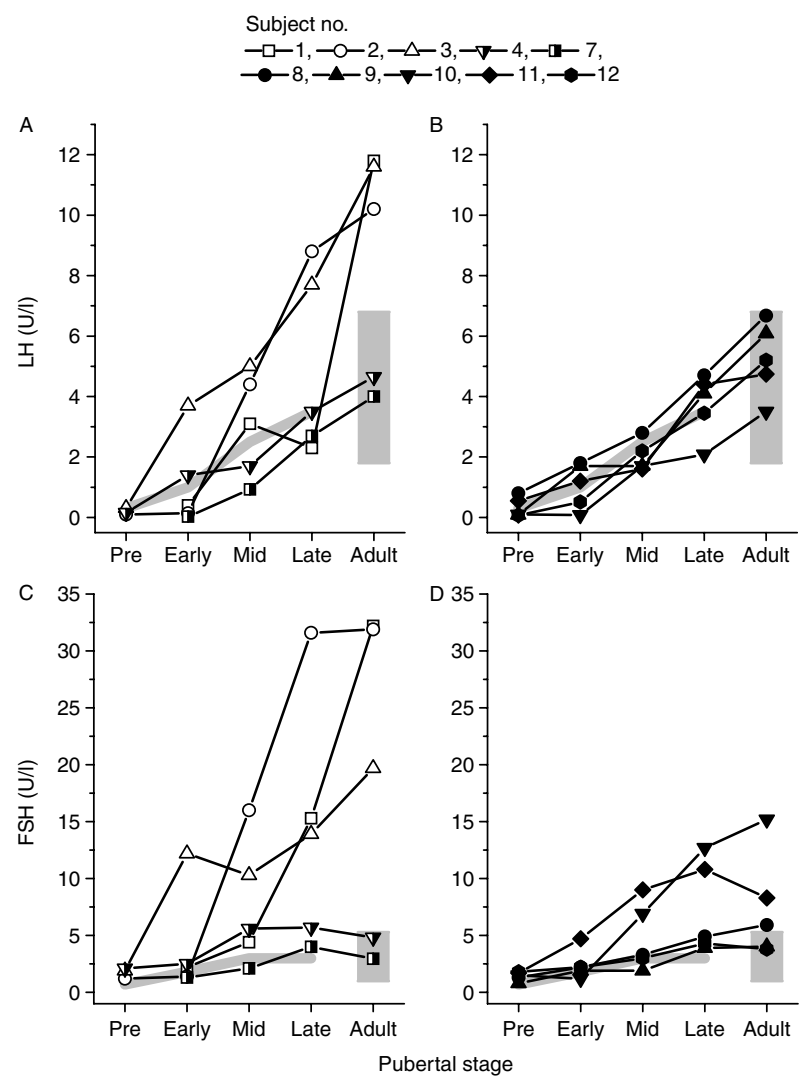

Figure 2 LH (upper panels) and FSH (lower panels) through the different pubertal stages in males with NS. Left-hand panels (A, C): Males with undescended testes (UT). Open symbols represent males with bilateral UT, the half-filled triangle represents the male who developed bilateral UT at a late stage and the half-filled square represents the patient with unilateral UT. Right-hand panels (B, D): Filled symbols represent males with descended testes. Grey lines represent mean daytime levels for healthy boys followed longitudinally. Grey areas represent 5th-95th percentiles for $\mathrm{LH}$ and FSH levels in healthy men.

\section{Pituitary function prior to and during pubertal development}

Individual serum concentrations of LH and FSH are shown in Fig. 2. LH and FSH levels did not differ from those of the healthy boys prior to puberty. During late puberty, two males with UT had elevated LH levels; LH levels had already started to increase in early/mid puberty. All subjects in the DT group had normal LH levels. Of the five subjects in the UT group, three had increased FSH levels from late puberty. Elevated FSH levels were also found from mid puberty in two subjects with DT, both had diminished testicular size when assessed as adults.

There were no differences in serum LH or FSH levels during puberty, when males with NS who had UT were compared to those who had DT (Table 2).

\section{Gonadal function prior to and during pubertal development}

Individual serum testosterone, $\mathrm{E}_{2}$, AMH and inhibin $\mathrm{B}$ concentrations in males with NS in relation to pubertal development are shown in Figs 3-5. Before puberty, testosterone, $\mathrm{E}_{2}$, $\mathrm{AMH}$ and inhibin $\mathrm{B}$ levels were within the expected range in almost all cases. Testosterone concentrations were elevated in one subject during early to mid puberty and in another subject prior to and during early puberty. All boys had testosterone concentrations within the normal range during late puberty. $\mathrm{E}_{2}$ concentrations were elevated during early, mid or late puberty for five of the ten males with NS. In half of the cases (both UT and DT), AMH and inhibin B levels declined to subnormal levels in advanced pubertal stages. The lowest inhibin B levels were found in the four subjects treated for bilateral UT and in the two males with DT, but diminished testes (subject no. 10 and 11).

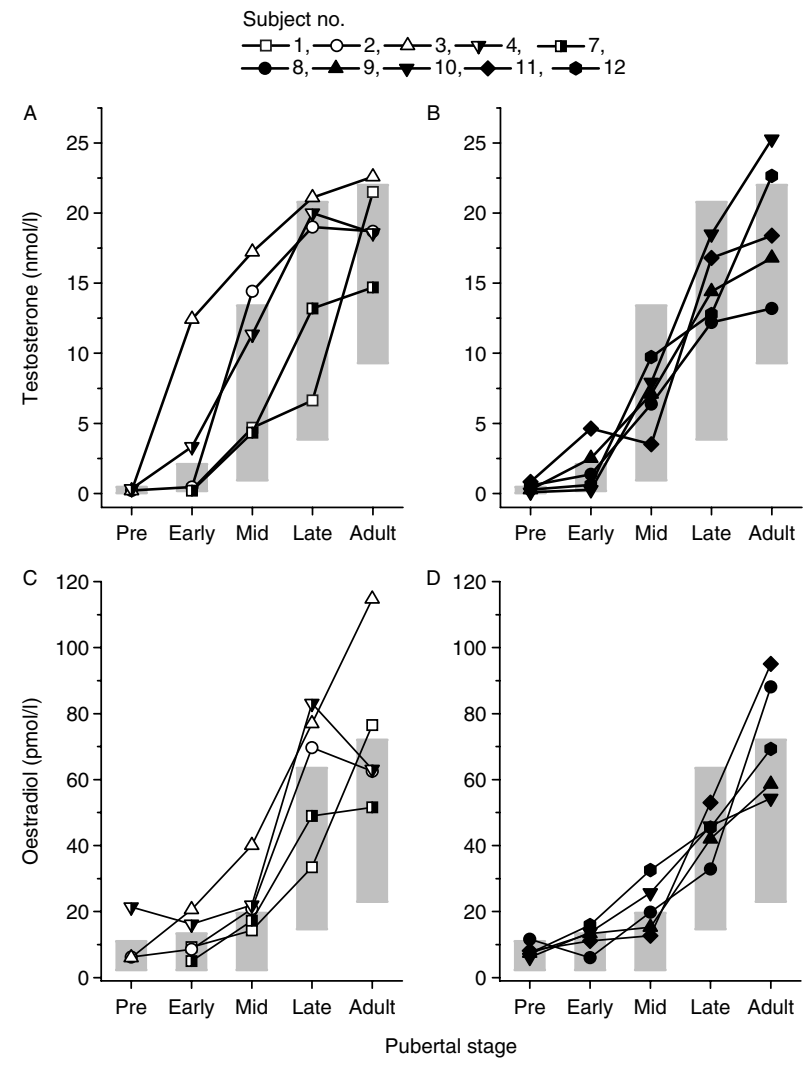

Figure 3 Longitudinal changes in serum testosterone (upper panels) and oestradiol (lower panels) concentrations in relation to pubertal stages in 10 males with NS. Left-hand panels (A, C): Males with undescended testes (UT). Open symbols represent males with bilateral UT, the half-filled triangle represents the male who developed bilateral UT at a late stage and the half-filled square represents the patient with unilateral UT. Right-hand panels (B, D): Filled symbols represent males with descended testes. Grey areas represent 5th-95th percentiles for min and max daytime (0800-1400 h) hormone levels in healthy boys and men. 


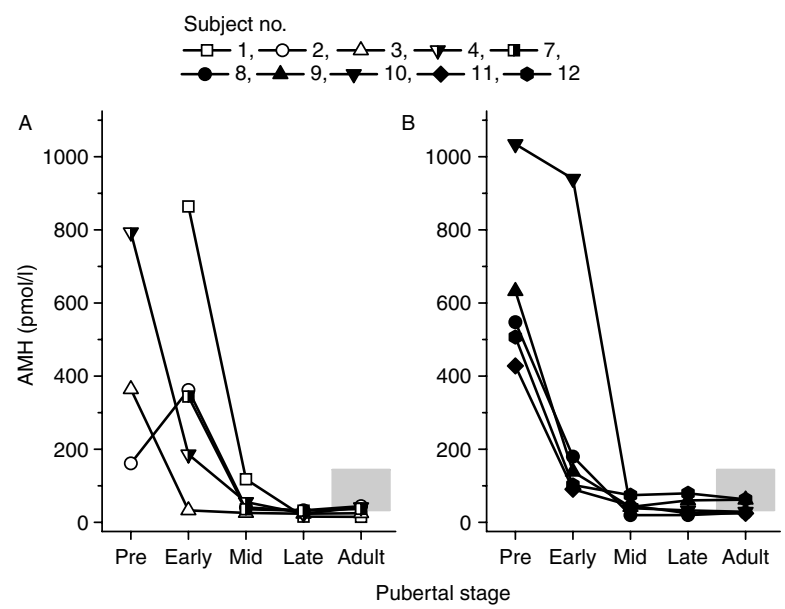

Figure 4 Anti-Müllerian hormone (AMH) concentrations in relation to pubertal stage in males with NS. Panel A: Males with undescended testes (UT). Open symbols represent males with bilateral UT, the half-filled triangle represents the male who developed bilateral UT at a late stage and the half-filled square represents the patient with unilateral UT. Panel B: Filled symbols represent males with descended testes. Grey areas represent 5th-95th percentiles for levels in healthy men.

There were no differences in serum testosterone, $\mathrm{E}_{2}$, AMH and inhibin B levels during puberty when males with NS with UT were compared to those who had DT (Table 2).

\section{Hormone levels in NS adults}

NS compared with controls Both males with NS as a group and the subgroup with UT had higher serum levels of $\mathrm{LH}, \mathrm{FSH}$, testosterone and $\mathrm{E}_{2}$ and lower levels of AMH inhibin B than controls (Table 3). Adult males with DT also had higher serum levels of FSH and $\mathrm{E}_{2}$ and lower levels of AMH and inhibin B than controls, but serum levels of LH and testosterone were normal (Table 3). Of the NS males, three (one with UT and two with DT) had all reproductive hormones within the normal range.

UT group compared with DT group In adulthood, there were no differences in serum LH, FSH, testosterone, $\mathrm{E}_{2}, \mathrm{AMH}$ and inhibin $\mathrm{B}$ levels between males with NS who had UT and those who had DT (Table 3).

\section{Genetic screening}

Of the 12 boys, five were found to have a mutation in the PTPN11 gene (Table 1). No other genes were tested. There was no association between reproductive hormones and PTPN11 gene mutation (data not shown).

\section{Discussion}

This longitudinal study is the first to describe the pituitary-gonadal endocrine changes during puberty in males with NS. Half of the studied group had UT and half had delayed puberty. Before puberty, reproductive hormone levels were within the expected range $(11,12$, 19, 24, 25). During puberty, most of the studied boys had small testes that, in the majority of cases, progressed to normal size at adulthood. No difference in hormone levels was observed between the UT and the DT groups, either during puberty or in adulthood. However, as adults, males with NS had higher LH, FSH, testosterone and $\mathrm{E}_{2}$ and lower $\mathrm{AMH}$ and inhibin B levels than controls. Overall, this study indicates Sertoli cell dysfunction in combination with impaired Leydig cell function in both NS groups, suggesting that UT is not the main contributing factor for impaired testicular function in males with NS.

The first overt sign of puberty in healthy boys is an increase in testicular volume, with Sertoli cells accounting for $93-95 \%$ of the seminiferous tubule cell mass, and germ cells accounting for $5-7 \%$ (27). During the months preceding this first pubertal sign, the gonadotropins have influenced the testes to develop and increase in size. This in turn results in increased testosterone production from the testes. The association between testicular volume and testosterone concentrations is strong during pubertal development (19). At the end of puberty, germ cell mass accounts for more than $90 \%$ of seminiferous tubule volume and Sertoli cells account for $<10 \%$. In this study, elevated testosterone and $E_{2}$ levels were found during pubertal development when testicular size was taken into account. Our findings indicate that these males do not have delayed gonadarche, but they do have reduced

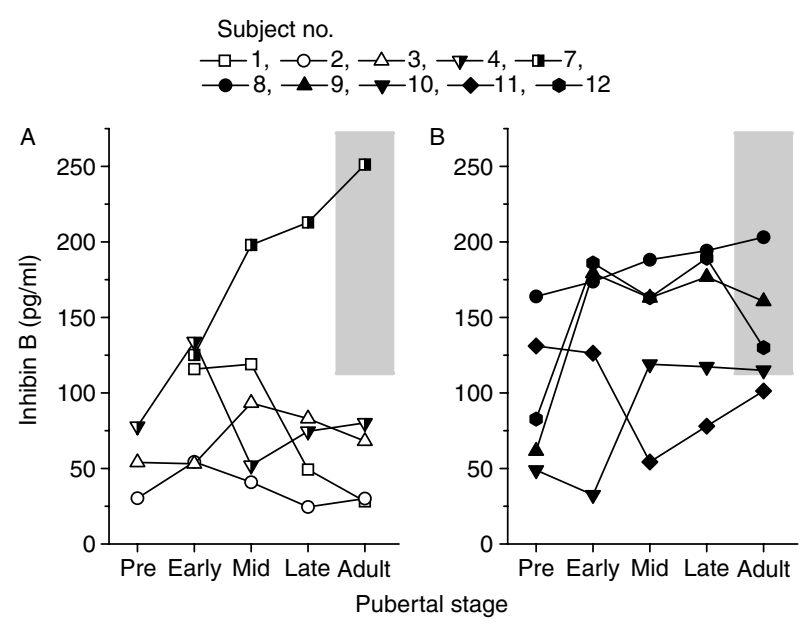

Figure 5 Inhibin $B$ concentrations in relation to pubertal stage in males with NS. Panel A: Males with undescended testes (UT). Open symbols represent males with bilateral UT, the half-filled triangle represents the male who developed bilateral UT at a late stage and the half-filled square represents the patient with unilateral UT. Panel B: Filled symbols represent males with descended testes. Grey areas represent 5th-95th percentiles for levels in healthy men. 
testicular volume. This is presumably due to impaired Sertoli cell function because their testicular volume is normal at adulthood. We believe that a deficit in Sertoli cell numbers, indicated in this study by elevated FSH and subnormal AMH and inhibin B levels, masks appropriate pubertal development. Thus, based on our results, it is preferable to assess pubertal maturation in boys with NS by sex steroid levels relative to appropriate paediatric reference intervals rather than by measurement of testicular size.

Several previous studies have indicated a strong association between subnormal inhibin B concentrations, elevated FSH concentrations and reduced fertility in otherwise healthy men $(13,15)$. It has also been reported that 40-50\% men who have formerly had bilateral UT were infertile, showing subnormal sperm counts and inhibin B levels, as well as elevated FSH levels but normal LH and testosterone levels $(7,16)$. Our results showed subnormal levels of inhibin B, elevated levels of LH and FSH but normal/high levels of testosterone and $\mathrm{E}_{2}$ in adult men with a history of UT, despite being surgically treated and having at least one testis with a normal volume. According to their hormonal status, they are anticipated to be infertile. The reason for this could be the surgery itself; however, UT is a frequent occurrence in NS $(60-77 \%)(3,5)$, and we postulate that UT may be a secondary manifestation of primary gonadal dysfunction. Our speculation is strengthened by the findings of elevated LH and highnormal testosterone levels, not consistent with bilateral UT alone $(7,16)$, indicating a Leydig cell hyperplasia.

NS is not a homogenous entity concerning genotype nor phenotype, although all mutations are within the RAS/MAPK pathway. Thus, our study may demonstrate a mixture of results from different circumstances. In favour of dysgenetic testes hypothesis, elevated $\mathrm{E}_{2}$, LH and FSH levels and subnormal AMH and inhibin B levels have previously been found in Klinefelter syndrome $(28,29)$. Similar to Klinefelter syndrome, NS males may have late-onset testicular dysgenesis. Before puberty, hormone levels were normal, but the declining $\mathrm{AMH}$ and inhibin $\mathrm{B}$ concentrations to subnormal levels in adults indicate that Sertoli and/or germ cell function progressively deteriorates, resulting in impaired spermatogenesis. Deterioration of Sertoli and germ cell function may be an explanation for the 'shrinking' testes in three of our patients and an early sign of senescence. In order to validate our results, further studies involving testicular biopsies are needed.

None of the subjects in this study were GH deficient. It has been speculated that GH treatment may influence the initiation or tempo of pubertal development in nonGHD children. Our unpublished data in short otherwise healthy children reveal that $\mathrm{GH}$ treatment did not influence age of puberty onset and did not accelerate pubertal timing. However, in boys, GH treatment seemed to increase testicular volume. Thus, we presume that $\mathrm{GH}$ treatment does not change the conclusions of this study.

Little data concerning correlations between gene mutation and gonadal function have been reported in subjects with NS. Some genotype-phenotype associations have been reported for other manifestations, including heart failure, cardiomyopathy, short stature, ectodermal features and haematological abnormalities (30), but there are no known associations between genes and pubertal development, UT or fertility. In our study, about $50 \%$ of the subjects have the PTPN11 mutation, which is as expected in the NS population (30), but we did not find any correlations between this genotype and gonadal function. The lack of an association between gonadal function and the PTPN11 mutation was also shown in a previous study in nine males (10).

The main strength of this study is the careful longitudinal record, with few missing observations, made of clinical findings and associated laboratory results in males with NS from childhood through to adulthood. The weakness of the study is the small number of observations and that may be the reason for lack of significances between the UT and DT groups. However, although hormonal abnormities are observed more frequently in those patients with UT, we still found some abnormal results in the DT group. This is in accordance with previous findings (10).

In conclusion, our data indicate that the declared delayed puberty, UT or infertility in males with NS is the result of a deficit in Sertoli and Leydig cell function. We suggest that the deficit in Sertoli cell numbers in NS males masks otherwise appropriate pubertal development. Moreover, NS males may have the same pattern of progressive deterioration in Sertoli cell function seen in other syndromes with late-onset testicular dysgenesis.

\section{Declaration of interest}

Novo Nordisk gave an unrestricted grant to perform the GH treatment study in the NS subjects as well as the analysis of genes. J Dahlgren received consulting fees for lectures and book chapters by Novo Nordisk, Pfizer, IPSEN and Merck Serono. C Ankarberg-Lindgren received consulting fees for lectures by Novo Nordisk.

\section{Funding}

This work was supported by grants from the Swedish Research Council (no. 522-7238) and by Novo Nordisk. We especially thank Dr AnneMarie Kappelgaard at Novo Nordisk also for her scientific support.

\section{Acknowledgements}

The authors thank the patients with Noonan syndrome and their parents for participating in this study. We thank the physicians who referred subjects from all over Sweden. The authors would also thank the staff at GP-GRC, Dr Hans Fors for the supply of samples from healthy males and Monika Eriksson at the laboratory, all at The Queen Silvia Children's Hospital, for their assistance and prof. Judith Allansson for review. 


\section{References}

1 Tartaglia M, Mehler EL, Goldberg R, Zampino G, Brunner HG, Kremer H, van der Burgt I, Crosby AH, Ion A, Jeffery S, Kalidas K, Patton MA, Kucherlapati RS \& Gelb BD. Mutations in PTPN11, encoding the protein tyrosine phosphatase SHP-2, cause Noonan syndrome. Nature Genetics 200129 465-468. (doi:10.1038/ ng772)

2 Theintz G \& Savage MO. Growth and pubertal development in five boys with Noonan's syndrome. Archives of Disease in Childhood 198257 13-17.

3 van der Burgt I. Noonan syndrome. Orphanet Journal of Rare Diseases 20072 4. (doi:10.1186/1750-1172-2-4)

4 Allanson JE. Noonan syndrome. American Journal of Medical Genetics. Part C, Seminars in Medical Genetics 2007 145C 274-279. (doi:10. 1002/ajmg.c.30138)

5 Jorge AA, Malaquias AC, Arnhold IJ \& Mendonca BB. Noonan syndrome and related disorders: a review of clinical features and mutations in genes of the RAS/MAPK pathway. Hormone Research 200971 185-193. (doi:10.1159/000201106)

6 Werder EA, Illig R, Torresani T, Zachmann M, Baumann P, Ott F \& Prader A. Gonadal function in young adults after surgical treatment of cryptorchidism. British Medical Journal 19762 1357-1359. (doi:10.1136/bmj.2.6048.1357)

7 Cortes D, Thorup J, Lindenberg S \& Visfeldt J. Infertility despite surgery for cryptorchidism in childhood can be classified by patients with normal or elevated follicle-stimulating hormone and identified at orchidopexy. BJU International $200391670-674$. (doi:10.1046/j.1464-410X.2003.04177.x)

8 Sinisi AA, Criscuolo T, Maresca F, Quarto C, Di Finizio B, Bellastella A \& Faggiano M. Endocrine profile in Noonan's syndrome. Minerva Endocrinologica 198712 13-17.

9 Elsawi MM, Pryor JP, Klufio G, Barnes C \& Patton MA. Genital tract function in men with Noonan syndrome. Journal of Medical Genetics 199431 468-470. (doi:10.1136/jmg.31.6.468)

10 Marcus KA, Sweep CG, van der Burgt I \& Noordam C. Impaired Sertoli cell function in males diagnosed with Noonan syndrome. Journal of Pediatric Endocrinology and Metabolism 200821 1079-1084. (doi:10.1515/JPEM.2008.21.11.1079)

11 Aksglaede L, Sorensen K, Boas M, Mouritsen A, Hagen CP, Jensen RB, Petersen JH, Linneberg A, Andersson AM, Main KM, Skakkebaek NE \& Juul A. Changes in anti-Mullerian hormone (AMH) throughout the life span: a population-based study of 1027 healthy males from birth (cord blood) to the age of 69 years. Journal of Clinical Endocrinology and Metabolism 2010 95 5357-5364. (doi:10. 1210/jc.2010-1207)

12 Andersson AM, Juul A, Petersen JH, Muller J, Groome NP \& Skakkebaek NE. Serum inhibin B in healthy pubertal and adolescent boys: relation to age, stage of puberty, and folliclestimulating hormone, luteinizing hormone, testosterone, and estradiol levels. Journal of Clinical Endocrinology and Metabolism 199782 3976-3981. (doi:10.1210/jc.82.12.3976)

13 Jensen TK, Andersson AM, Hjollund NH, Scheike T, Kolstad H, Giwercman A, Henriksen TB, Ernst E, Bonde JP, Olsen J, McNeilly A, Groome NP \& Skakkebaek NE. Inhibin B as a serum marker of spermatogenesis: correlation to differences in sperm concentration and follicle-stimulating hormone levels. A study of 349 Danish men. Journal of Clinical Endocrinology and Metabolism 199782 4059-4063. (doi:10.1210/jc.82.12.4059)

14 Grinspon RP \& Rey RA. Anti-Mullerian hormone and Sertoli cell function in paediatric male hypogonadism. Hormone Research in Paediatrics 201073 81-92. (doi:10.1159/000277140)

15 Halder A, Fauzdar A \& Kumar A. Serum inhibin B and folliclestimulating hormone levels as markers in the evaluation of azoospermic men: a comparison. Andrologia 200537 173-179. (doi:10.1111/j.1439-0272.2005.00677.x)

16 Lee PA, Coughlin MT \& Bellinger MF. Inhibin B: comparison with indexes of fertility among formerly cryptorchid and control men. Journal of Clinical Endocrinology and Metabolism 200186 2576-2584. (doi:10.1210/jc.86.6.2576)
17 Osio D, Dahlgren J, Wikland KA \& Westphal O. Improved final height with long-term growth hormone treatment in Noonan syndrome. Acta Paediatrica 200594 1232-1237. (doi:10.1080/ $08035250510031476)$

18 Prader A. Testicular size: assessment and clinical importance. Triangle $19667240-243$.

19 Ankarberg-Lindgren C \& Norjavaara E. Changes of diurnal rhythm and levels of total and free testosterone secretion from pre to late puberty in boys: testis size of $3 \mathrm{ml}$ is a transition stage to puberty. European Journal of Endocrinology 2004151 747-757. (doi:10.1530/eje.0.1510747)

20 Marshall WA \& Tanner JM. Variations in the pattern of pubertal changes in boys. Archives of Disease in Childhood 197045 13-23. (doi:10.1136/adc.45.239.13)

21 Ankarberg-Lindgren C \& Norjavaara E. A purification step prior to commercial sensitive immunoassay is necessary to achieve clinical usefulness when quantifying serum 17 beta-estradiol in prepubertal children. European Journal of Endocrinology 2008158 117-124. (doi:10.1530/EJE-07-0403)

22 Ankarberg C \& Norjavaara E. Diurnal rhythm of testosterone secretion before and throughout puberty in healthy girls: correlation with 17beta-estradiol and dehydroepiandrosterone sulfate. Journal of Clinical Endocrinology and Metabolism $1999 \mathbf{8 4}$ 975-984. (doi:10.1210/jc.84.3.975)

23 Zachmann M, Prader A, Kind HP, Hafliger H \& Budliger H. Testicular volume during adolescence. Cross-sectional and longitudinal studies. Helvetica Paediatrica Acta 197429 61-72.

24 Albertsson-Wikland K, Rosberg S, Lannering B, Dunkel L, Selstam G \& Norjavaara E. Twenty-four-hour profiles of luteinizing hormone, follicle-stimulating hormone, testosterone, and estradiol levels: a semilongitudinal study throughout puberty in healthy boys. Journal of Clinical Endocrinology and Metabolism $1997 \mathbf{8 2}$ 541-549. (doi:10.1210/jc.82.2.541)

25 Ankarberg-Lindgren C \& Norjavaara E. Twenty-four hours secretion pattern of serum estradiol in healthy prepubertal and pubertal boys as determined by a validated ultra-sensitive extraction RIA. BMC Endocrine Disorders 20088 10. (doi:10. 1186/1472-6823-8-10)

26 Allvin K, Ankarberg-Lindgren C, Fors H \& Dahlgren J. Elevated serum levels of estradiol, dihydrotestosterone, and inhibin $\mathrm{B}$ in adult males born small for gestational age. Journal of Clinical Endocrinology and Metabolism 200893 1464-1469. (doi:10. 1210/jc.2007-1743)

27 Rey RA, Campo SM, Bedecarras P, Nagle CA \& Chemes HE. Is infancy a quiescent period of testicular development? Histological, morphometric, and functional study of the seminiferous tubules of the cebus monkey from birth to the end of puberty Journal of Clinical Endocrinology and Metabolism $1993 \quad 76$ 1325-1331. (doi:10.1210/jc.76.5.1325)

28 Wikstrom AM, Dunkel L, Wickman S, Norjavaara E, AnkarbergLindgren C \& Raivio T. Are adolescent boys with Klinefelter syndrome androgen deficient? A longitudinal study of Finnish 47 . XXY boys. Pediatric Research 200659 854-859. (doi:10.1203/ 01.pdr.0000219386.31398.c3)

29 Bastida MG, Rey RA, Bergada I, Bedecarras P, Andreone L, del Rey G, Boywitt A, Ropelato MG, Cassinelli H, Arcari A, Campo S \& Gottlieb S. Establishment of testicular endocrine function impairment during childhood and puberty in boys with Klinefelter syndrome. Clinical Endocrinology 200767 863-870. (doi:10.1111/j.1365-2265.2007.02977.x)

30 Romano AA, Allanson JE, Dahlgren J, Gelb BD, Hall B, Pierpont ME, Roberts AE, Robinson W, Takemoto CM \& Noonan JA. Noonan syndrome: clinical features, diagnosis, and management guidelines. Pediatrics 2010126 746-759. (doi:10. 1542/peds.2009-3207)

Received 27 April 2011

Accepted 5 May 2011 